\title{
HISTORICIDADE DOS CURSOS DE LICENCIATURA NO BRASIL E SUA REPERCUSSÃO NA FORMAÇÃO DO PROFESSOR DE QUÍMICA
}

\section{HISTORICITY OF THE UNDERGRADUATE COURSES FOR TEACHER TRAINING IN BRAZIL AND ITS REPERCUSSION IN THE TRAINING OF THE TEACHER OF CHEMISTRY}

\author{
José Ossian Gadelha de Lima \\ Universidade Estadual do Ceará, jose.lima@uece.br \\ Luciana Rodrigues Leite \\ Universidade Estadual Vale do Acaraú, luciana leite@uvanet.br
}

\section{Resumo}

A formação de professores em nível superior no Brasil constitui uma temática muito polêmica. Quando essas discussões são expandidas para o âmbito da formação do professor de Química, o cenário apresenta-se ainda mais complexo e contraditório. Mediante esse contexto, o propósito desse artigo é evidenciar, por meio de um estudo bibliográfico, as conjunturas nas quais a formação do professor de Química vem se edificando. Para tanto, são destacados aspectos da história educacional brasileira, com foco na constituição dos cursos de licenciatura como via formativa do professorado, dando ênfase à morosidade, descontinuidades e descaso com que essa formação vem sendo tratada no decorrer do tempo, ressaltando especialmente aspectos inerentes à Educação Básica e ao contexto social e econômico do país, que serviram como plano de fundo para a implantação das políticas de formação docente. O cenário exposto revela que os vestígios históricos ainda ecoam sobre a formação atual desses profissionais e, especialmente, que os cursos de Licenciatura em Química não conseguiram se desvincular das características bacharelescas que neles habitam desde sua origem.

Palavras-chave: história. Formação inicial. Educação superior. Ensino de Química.

\section{Abstract}

The training of teachers at higher education level in Brazil is a very controversial subject. When these discussions are expanded to the ambit of the training of chemistry teacher, the scenario is even more complex and contradictory. In light of this context, the purpose of this article is to highlight through a bibliographical study the conjunctures in which the formation of the teacher of Chemistry is being built. Therefore, aspects of the Brazilian educational history are highlighted, with a focus on the constitution of the degree courses as a formative journey of teachers, emphasizing the slowness, discontinuities and neglect with which this training has been treated over time, especially highlighting aspects inherent in Basic Education and the social and economic context of the country, which served as a 
background for the implementation of teacher training policies. The exposed scenario reveals that the historical vestiges still echo in the current formation of these professionals, and especially it shows that the courses of Degree in Chemistry have not been able to break free of the baccalaureate characteristics that dwell in them since its origin.

Keywords: history. Initial training. Higher Education. Chemistry teaching.

\section{Introdução}

Apesar dos avanços promovidos nos últimos anos na legislação educacional, os problemas referentes à formação de professores da Educação Básica, no Brasil, atravessam décadas. Segundo Imbernón (2011), historicamente essa temática sempre esteve situada no contexto de um discurso ambivalente, paradoxal e contraditório, possuindo de um lado a retórica histórica da importância dessa formação e de outro a realidade da miséria social e acadêmica que the foi concedida.

Para ilustrar esse cenário, pode-se mencionar o fato da formação de professores em nível superior no Brasil corresponder a um processo tardio e concebido com base na racionalidade técnica. Um percurso bem mais complexo se refere à formação do professor de Química, que teve a implantação de seus primeiros cursos se efetivando somente em 1934, ou seja, quase 400 anos após a chegada dos jesuítas ao país e a consequente criação das primeiras 'escolas de ler e escrever'.

Atualmente, embora o número de cursos de Licenciatura em Química tenha aumentado substancialmente, esses e os demais cursos de licenciatura do país convivem com outras problemáticas, tais como a desconsideração do repertório de conhecimentos dos professores em formação; tratamento inadequado dos conteúdos, com ênfase no pedagogismo ou no conteudismo; inadequação do tratamento da pesquisa, mediante a dissociação teórico-prática; concepção restrita de prática pedagógica; ausência de conteúdos relativos às tecnologias da informação e das comunicações; desconsideração das especificidades próprias dos níveis e/ou modalidades de ensino em que são atendidos os alunos da Educação Básica e das especificidades próprias das etapas desse nível escolar, dentre outras (BRASIL, 2002a).

Diante desse contexto, o artigo em questão tem o propósito de evidenciar, por meio de um estudo bibliográfico, aspectos inerentes à formação dos professores de Química no Brasil, construindo, deste modo, um retrospecto histórico que permeia desde os períodos em que predominava a ausência de formação específica destes profissionais até análises de políticas de formação docente implantadas no decorrer da história educacional do país.

Para a composição dessas discussões, muito embora a compreensão do processo de constituição e implantação dos cursos de formação em nível superior seja o foco do trabalho, foram utilizados como suporte aspectos inerentes à Educação Básica e ao contexto social e econômico do país, que serviram como plano de fundo para a implantação da legislação educacional e das políticas de formação docente. 


\section{Da ausência de formação específica aos primeiros ensaios}

O percurso da formação docente no Brasil teve seus prelúdios focados no professorado do Ensino Primário, uma vez que o Ensino Secundário, mediante a finalidade de "[...] formar as individualidades condutoras [...]" do país (BRASIL, 1942), ficou por muito tempo restrito à elite. Nesse contexto, Vicentini e Lugli (2009) asseguram que o Brasil vivenciou um longo período de sua história sem a efetivação de "[...] um currículo específico, ou seja, um corpo de saberes socialmente aceito como próprio para capacitar o trabalho de ensinar" (p. 27). Contudo, mesmo tardiamente, a exigência de formação de profissionais da educação em nível superior emergiu em consequência da busca pela regulamentação do preparo de docentes para a escola secundária.

Corroborando essa assertiva, Saviani (2009) reitera que, somente após a independência do país, a questão do preparo de professores emergiu de forma explícita em solo brasileiro, com sua gênese envolta na implantação de um modelo formativo exclusivamente prático, consubstanciado pela Lei das Escolas de Primeiras Letras, promulgada em 15 de outubro de 1827. Por meio dessa lei foi estabelecido que o ensino nas Escolas Primárias deveria ser desenvolvido pelo método mútuo, e que "[...] os docentes deveriam ser treinados nesse método, às próprias custas, nas capitais das respectivas províncias [...] (p. 144).

Posteriormente, foram adotados o modelo de Escolas Normais (implantado a partir de 1834, com ênfase no domínio dos conhecimentos a serem transmitidos e não no preparo didático-pedagógico dos docentes) e os Institutos de Educação que, sob influência dos ideários da Escola Nova, começaram a ser instalados em 1932, evidenciando, finalmente, características que direcionavam a educação brasileira rumo à consolidação de um modelo pedagógico de formação docente (SAVIANI, 2013).

Também na década de 1930 foram criados os primeiros cursos de Licenciatura do país, sendo ofertados pelas Faculdades de Filosofia, Ciências e Letras existentes nas instituições de Ensino Superior (MESQUITA; SOARES, 2011), e organizados com base nos preceitos dos Institutos de Educação de São Paulo e do Distrito Federal (SAVIANI, 2009). Neste processo, um marco importante deve ser destacado, a Reforma Francisco Campos, a qual, por meio do Decreto-Lei $n^{\circ} 19.851 / 31$ (BRASIL, 1931a), tratou da primeira reestruturação da Educação Superior brasileira.

Neste mesmo período, por meio do Decreto-Lei $n^{\circ}$ 19.890/31 (BRASIL, 1931b), foram propostas novas deliberações sobre a organização do Ensino Secundário, que passou a ser constituído por dois cursos seriados: o fundamental, de cinco anos, e o complementar, de dois anos. Dentre as determinações mais relevantes desta lei, estava a valorização do Ensino de Ciências (termo que ao longo desse texto se refere ao ensino das disciplinas que formam o conjunto atualmente conhecido como 'Ciências da Natureza': física, química e biologia), estabelecendo, por exemplo, a obrigatoriedade da disciplina de Química nas três séries finais da etapa fundamental e nas duas séries da etapa complementar para o ingresso nos cursos superiores de medicina, farmácia, odontologia, engenharia e arquitetura. Ainda segundo este decreto-lei, o professor estaria habilitado para lecionar nesse nível escolar mediante uma formação específica no âmbito das Faculdades de Filosofia, Ciências e Letras. 
Dessa maneira, a ampliação da carga horária das disciplinas de Ciências no currículo do Ensino Secundário, associada à exigência de uma habilitação específica para lecionar nas suas séries, advertia para a necessidade de criação de instituições e cursos que atendessem esta demanda. No entanto, a concretização dessa gênese ocorreu lentamente, tanto que o funcionamento das Faculdades de Filosofia foi regulamentado somente por meio do Decreto-Lei n 1.190, de 04 de abril de 1939 (BRASIL, 1939).

A partir desse decreto foram estabelecidas no país, mesmo que indiretamente, as primeiras orientações legais sobre os cursos de formação docente em nível superior, pois nessa legislação vinha explicitado que uma das finalidades das Faculdades de Filosofia era preparar candidatos ao magistério do Ensino Secundário e Normal. Assim, essas faculdades deveriam ser organizadas em seções (Filosofia, Ciências, Letras e Pedagogia) e dentro de cada uma estariam distribuídos os cursos a serem ofertados. Na seção de ciências foram incluídos os cursos de Matemática, Física, Química, História Natural, Geografia e História, Ciências Sociais (BRASIL, 1939).

Apesar da lentidão burocrática e operacional, os dois primeiros cursos de Licenciatura em Química brasileiros foram criados em 1934 na Universidade de São Paulo (USP) (seu funcionamento só teve início em 1935) e em 1935 na Universidade do Distrito Federal (UDF), no Rio de Janeiro. A estrutura desses cursos, porém, antes e depois do Decreto-Lei $n^{\circ} 1.190 / 39$, não apresentava grandes diferenças do modelo $3+1$, em que os estudantes cursavam disciplinas científicas ou conteudistas durante 03 anos e disciplinas didáticas ou pedagógicas durante 01 ano, haja vista que o foco das Faculdades de Filosofia estava voltado para os cursos de bacharelado. Desse modo, após o estudo das disciplinas científicas, o estudante recebia o diploma de licenciado, o qual, naquela época, não apresentava o mesmo significado que o atual, referindo-se à 'licença cultural ou científica' adquirida pelo estudante. E somente ser-Ihe-ia conferida a licença para lecionar, caso ele tivesse interesse e seguisse o curso de Didática pelo período de 01 ano (OSÓRIO, 2009).

Terrazan et al. (2008) destacam que estas características evidenciam o caráter secundário com que a formação docente veio sendo tratada desde os prelúdios da história educacional do país, pois os cursos de bacharelado emergiram como uma opção natural de ingresso na formação profissional, enquanto os de licenciatura foram encarados como simples adendos àqueles. Dias-da-Silva (2005, p. 386) corrobora com esta assertiva ao destacar que "[...] a criação dos cursos de licenciatura aparece muito mais como um ônus que os cientistas pagaram para consolidar seus projetos de formação dos bacharéis [...]", do que como uma política de valorização do magistério.

Para acentuar este quadro desolador, o processo de expansão das Faculdades de Filosofia foi lento, tanto que até 1950, em todo o país, existiam somente 22 destas faculdades. Embora na década seguinte esse número tenha triplicado, os cursos de Química não acompanharam o processo de expansão, visto a necessidade de um suporte operacional oneroso para sua implantação e funcionamento, constituído por laboratórios, equipamentos, reagentes e manutenção (CANDAU, 1988).

Nesse contexto, o percurso de multiplicação dos cursos de Licenciatura em Química pelo país foi transcorrendo paulatinamente, de modo que até 1965, em um total de 37 universidades existentes no país (MENDONÇA, 2000), somente 13 ofereciam esse curso. Dessas, apenas duas estavam localizadas em cidades do interior (Universidade Federal de 
Juiz de Fora e Universidade Federal de Santa Maria) (BARROSO; FERNANDES, 2006; BRASIL, 2017), já que as demais foram fundadas em capitais devido à expansão do número de escolas primárias e secundárias concentradas nas regiões urbanas e, consequentemente, à necessidade de professores formados nas diversas áreas do conhecimento para atender essa demanda (ARANHA, 2006).

\section{A renovação do Ensino de Ciências no Brasil e suas repercussões na formação docente}

Ao analisar a educação brasileira no período compreendido entre 1930 e 1964, Zotti (2004) destaca, como características marcantes do Ensino Secundário da época, o caráter elitista, acadêmico, propedêutico e de base humanista, assim como a natureza da erudição na transmissão dos conhecimentos das Ciências dispostos nos livros didáticos.

Mediante essa conjuntura, a necessidade de reestruturação de todo o ensino brasileiro se mostrava eminente, no entanto, mais uma vez, o governo preferiu trilhar o caminho das reformas parciais em vez de consolidar uma reorganização geral de todo o sistema (ROMANELLI, 2007). Nesse intento, foram lançados uma série de dispositivos legais, dentre os quais estava o Decreto-Lei $n^{\circ} 4.244 / 42$ instituindo a Reforma Capanema, que trouxe alterações a serem implantadas, de um modo geral, no Ensino Secundário e, especificamente, no Ensino de Ciências.

Com a implementação dessa reforma, o Ensino Secundário passou a ser dividido em dois ciclos, sendo o primeiro chamado de 'curso ginasial' (de quatro anos) compreendendo uma só modalidade, e o segundo (de três anos), abrangendo duas modalidades: 'curso clássico' e 'curso científico' (BRASIL, 1942). Isso acarretou um aumento significativo no número de disciplinas científicas, contribuindo, consequentemente, para o aumento da necessidade de formação de professores dessa área.

Todavia, de acordo com Zotti (2004), esta reforma não surtiu o efeito desejado, haja vista que, na prática, ao invés de atingir seu objetivo (superar o caráter propedêutico do Ensino Secundário e ressaltar sua função educativa), instaurou uma matriz curricular enciclopédica, abrangendo finalidades ligadas à formação geral e específica do estudante. Romanelli (2007, p. 157) corrobora essa assertiva, reiterando que "[...] essa lei nada mais fazia do que acentuar a velha tradição do ensino secundário acadêmico, propedêutico e aristocrático [...]".

Nesse contexto, foi somente a partir de 1946, com a criação do Instituto Brasileiro de Educação, Ciência e Cultura (IBECC), que ocorreu uma das tentativas de modificar a realidade do Ensino de Ciências posto nos currículos das escolas brasileiras (BRASIL, 1946), de modo que se transformou em uma experiência institucional inovadora, sobretudo a partir da década de 1950, quando diante do reconhecimento da precariedade do ensino brasileiro, esse Instituto assumiu a tarefa de modificá-lo, com o principal intuito de "[...] promover a melhoria da formação científica dos alunos que ingressariam nas instituições de ensino superior e, assim, contribuir de forma significativa ao desenvolvimento nacional" (BARRA; LORENZ, 1986, p. 1971).

Esse período marca o início da renovação do Ensino de Ciências no Brasil, a qual está relacionada ao contexto de mudanças efetivadas no cenário internacional de 
industrialização e ao desenvolvimento científico e tecnológico que ocorreu após a Segunda Guerra Mundial. Essas mudanças influenciaram os currículos escolares, pois havia a necessidade de incorporação da nova gama de conhecimentos científicos descobertos nessa época. O IBECC veio então contribuir para a implementação dessas mudanças, passando a desenvolver projetos de divulgação científica e de Educação em Ciências, acompanhados da elaboração de material didático (KRASILCHIK, 2000).

A implementação dessas e outras ações estava atrelada, segundo Chassot (2004), ao entendimento de que as desvantagens tecnológicas brasileiras, em relação a outros países, decorriam, em parte, de uma educação deficitária em Ciências. Lorenz (2008) ainda destaca que, na década seguinte, esse movimento de renovação teve continuidade de um modo mais amplo, pois o sucesso técnico-científico da União Soviética com o lançamento do Sputinik, em 1957, colocou este país em primeiro lugar na corrida espacial, o que motivou organizações internacionais a patrocinarem encontros, debates e estudos sobre 0 Ensino de Ciências, no intuito de reduzir a distância entre os países ocidentais e a União Soviética. Esses encontros resultaram em grandes projetos curriculares, com a produção de materiais didáticos inovadores que foram traduzidos e introduzidos nas escolas brasileiras pelo IBECC.

No começo da década de 1960, após 13 anos de tramitação, em um longo trajeto de discussões e conflitos, foi promulgada a primeira Lei de Diretrizes e Bases (LDB) da Educação Nacional (Lei $n^{\circ} 4.024 / 61$ ) que, dentre outras determinações, reestruturava 0 sistema educacional brasileiro em ensino primário (de quatro anos), médio (de sete anos) e superior. O Ensino Médio continuou sendo ministrado em dois ciclos, ginasial (quatro anos) e colegial (três anos). Além disso, essa lei ampliava a participação das Ciências no currículo escolar, passando essa disciplina a figurar desde o $1^{\circ}$ ano do curso ginasial. Houve também um aumento da carga horária das disciplinas de Física, Química e Biologia ministradas no curso colegial, possibilitando mais liberdade às escolas na escolha dos conteúdos a serem desenvolvidos em seus programas (BRASIL, 1961).

O IBECC utilizou então essa conjuntura para introduzir nas escolas brasileiras os materiais curriculares norte-americanos, denominados na literatura especializada de 'sopa alfabética', uma vez que os projetos de Física (Physical Science Study Commitee - PSSC), Biologia (Biological Science Curriculum Study - BSCS), Química (Chemical Bond Approach - CBA) e Matemática (Science Mathematics Study Group - SMSG) eram conhecidos universalmente por suas siglas (KRASILCHIK, 2000).

A LDB no 4.024/61 também estabeleceu que os dois ciclos, ginasial e colegial, abrangeriam os cursos secundários, técnicos e de formação de professores para o Ensino Primário e Pré-Primário, dentre outros (Art. 34) (BRASIL, 1961). A inclusão da modalidade profissionalizante como optativa, dando origem a uma dualidade, ocorreu devido a não existência de vagas suficientes nas universidades para atender a todos os estudantes egressos desse nível escolar. Esse dualismo é explicitado por Souza (2008) quando enfatiza que essa LDB permitiu a democratização do Ensino Médio no intuito de oferecer formação especializada a alunos provindos das classes menos abastadas, de modo que 0 acesso ao nível superior continuava restrito às classes dominantes.

Seguindo esta mesma perspectiva, Saviani (2009, p. 149) reitera que "[...] sob a hegemonia de uma elite de corte liberal-burguês, a escola secundária foi definida como o 
lugar da distinção de classe cujo papel é garantir aos membros da elite o domínio daqueles conteúdos que a distinguem do povo-massa [...]". Distinção que foi acentuada pelos benefícios trazidos pela primeira LDB ao setor privado de ensino, contribuindo para a disseminação dessas instituições por todo o território brasileiro.

A expansão das instituições de ensino privado ocorreu de forma mais efetiva a partir do aumento da população escolar, pós implantação do regime militar, em 1964. É nesse período que "[...] acontece a massificação da escola, com efeitos de reprodução social, mas também de democratização [...]" (CHARLOT, 2007, p. 130), em um contexto que passa a requerer um maior número de professores para atender à crescente demanda do público escolar e sobreleva, demasiadamente, a falta de cursos de formação de professores para lecionar as disciplinas científicas. Vale ressaltar que, em um primeiro momento, a expansão das instituições privadas não contemplou os cursos de formação de professores de Química, devido ao caráter estrutural físico que demandava a implantação desses cursos.

O aumento da demanda por profissionais da educação, com o passar do tempo, foi se tornando um grave problema, de modo que a busca por uma solução se efetivou "[...] principalmente pela expansão do ensino universitário privado com a criação indiscriminada de cursos de licenciatura de curta duração em faculdades isoladas e pela permissão do exercício profissional de docentes não-habilitados [...]" (NASCIMENTO; FERNANDES; MENDONÇA, 2010, p. 234). Esses cursos foram implantados a partir de 1965 e, embora tenham contribuído para descaracterizar e desvalorizar ainda mais a profissão docente, deixaram de existir somente com a LDB n 9.394/96 (VICENTINI; LUGLI, 2009).

Dentre as medidas governamentais que se destacaram nessa época, e estão relacionadas à formação de professores para lecionar disciplinas científicas, é possível citar a criação, em 1965, de seis Centros de Ciências nas principais capitais brasileiras: Recife, Salvador, Belo Horizonte, Rio de Janeiro, São Paulo e Porto Alegre. Segundo Nardi (2005, p. 69), esses centros "[...] tinham como objetivo treinar professores e produzir e distribuir livros-texto e materiais de laboratório para as escolas de seus respectivos estados".

Em 1967 também foi criada a Fundação Brasileira para o Desenvolvimento do Ensino de Ciências (FUNBEC) que, a priori, destinou-se a industrializar os materiais produzidos pelo IBECC e realizar cursos para professores primários. Posteriormente, passou a produzir programas específicos para o Ensino Superior, constituindo-se em uma continuidade dos projetos de educação do IBECC (LORENZ, 2008).

Todas essas ações resultaram de acordos firmados entre o Ministério da Educação (MEC) e a agência norte-americana USAID (United States Agency for International Development). Nesses acordos, a USAID forneceu assessoria técnica e financeira, disseminando no Brasil as concepções de organização social, política e econômica que prevaleciam nos Estados Unidos, gerando intensas modificações no sistema educacional brasileiro que culminaram na Reforma do Ensino Superior promovida em 1968, e na Reforma dos Níveis Fundamental e Médio, ocorrida em 1971 (ROMANELLI, 2007).

\section{A formação docente a partir da Reforma do Ensino Superior}

Promulgada no final da década de 1960, a Lei $n^{\circ}$ 5.540/68 promoveu uma reestruturação no Ensino Superior brasileiro vigente até então, além de estabelecer, entre 
outras normas, que a formação de professores em nível superior para atuar na escola média poderia concentrar-se em um só estabelecimento isolado ou resultar da cooperação de vários (Art. 30). Ainda segundo essa legislação, os cursos de formação docente passavam a ser responsabilidade das Unidades Acadêmicas que integravam as instituições de ensino superior, tanto públicas quanto privadas (estas últimas, a partir de então, com apoio institucionalizado do Estado), e cujas disciplinas curriculares estavam sob sua responsabilidade (BRASIL, 1968). Estariam envolvidas, portanto, as unidades responsáveis pela formação do professor em relação aos conteúdos específicos (Exemplo: Instituto de Química, Instituto de Física, etc.; alguns originados a partir das antigas Faculdades de Filosofia) e as unidades responsáveis pela formação docente em relação aos conteúdos pedagógicos (Centros de Educação, Faculdades de Educação, etc.).

De acordo com Libâneo (2015), essa divisão da formação docente em duas (ou mais) unidades distintas fez com que o distanciamento entre disciplinas pedagógicas e científicas se sobrelevasse. Além disso, nesse período, não havia professores formados em quantidade suficiente para atender a demanda dos outros níveis de ensino que continuavam em expansão, de modo que outras medidas precisaram ser tomadas para resolver esse impasse.

Assim, as Unidades Acadêmicas responsáveis pelas disciplinas específicas passaram a dividir espaço formativo com as Faculdades e/ou Centros de Educação, de modo que, no tocante ao ensino das disciplinas de Química, Física e Biologia, a situação se tornou crítica, pois as poucas Unidades que ofertavam cursos de formação de professores nessa área estavam concentradas nos grandes centros urbanos, gerando um número significativo de formados nessas regiões e uma carência expressiva desses profissionais naquelas mais afastadas dos grandes centros. Além disso, diferentemente do primeiro período desta década (1960 - 1964), em que o número de vagas oferecidas no Ensino Superior cresceu praticamente $63,90 \%$ em relação à década anterior, a situação não só se inverteu no período seguinte (1964 - 1968), como se agravou profundamente, pois o aumento de $120 \%$ na demanda foi respondido com uma oferta de apenas $52,76 \%$, percentagem essa que demonstrou um decréscimo de $11,14 \%$ no ritmo de oferta em relação ao período anterior, gerando contestações e manifestações estudantis (ROMANELLI, 2007).

Na década seguinte, 1970, os ensinos primário e médio também passaram por uma reestruturação a partir da LDB $n^{\circ} 5.692 / 71$, a qual alterou esses níveis escolares para Ensino de Primeiro Grau (de oito anos) e Segundo Grau (de três ou quatro anos, conforme a habilitação). No tocante ao ensino das disciplinas científicas, as alterações foram profundas, pois estas adquiriram um caráter profissionalizante e tiveram seu espaço reduzido, sendo regulamentado que, nas quatro últimas séries do primeiro grau, os seus conteúdos constituiriam uma área de conhecimentos afins, de modo que as Ciências Físicas e Biológicas (Biologia, Física e Química), a Matemática e o Programa de Saúde deveriam ser estudados de forma integrada. Enquanto isso, esses conteúdos apareceram no Segundo Grau na forma de 'disciplinas', como a Biologia, a Física e a Química (BRASIL, 1971).

Imprudentemente, o artigo 78 desta LDB regulamentou que, na ausência de profissionais habilitados, poderiam exercer a docência aqueles que fossem aprovados em exames de suficiência regulados pelo Conselho Federal de Educação (CFE). Desta forma, 
estava garantida a permanência dos professores leigos. Além disso, diante do quadro de falta de professores, essa lei abriu prerrogativas para a regulamentação das licenciaturas curtas, que foram instituídas oficialmente por meio do Parecer n 895/71, de 09 de dezembro de 1971 (BRASIL, 1971).

Sob a égide de um caráter emergencial e experimental, o modelo formativo das licenciaturas curtas se destacou pelo seu amplo alcance em todo o território nacional, principalmente em regiões que não havia cursos de licenciatura que atendessem as necessidades locais, como já condicionado pela Lei n 5.692/71 (MESQUITA; SOARES, 2011). Em seu artigo 29, ela instituiu que a formação de professores para o ensino de Primeiro e Segundo Graus deveria ser realizada em níveis que se elevariam progressivamente, de modo a se adequar às diferenças culturais de cada região do país (BRASIL, 1971).

O argumento utilizado para a implantação das licenciaturas curtas se baseou no princípio de que mais valeria uma formação aligeirada do que formação nenhuma (NASCIMENTO, 2012). Essa característica evidencia a visão pedagógica assumida durante aquele período, a qual estava baseada em uma "[...] concepção produtivista da educação [...]", que dentre outras peculiaridades buscava o "[...] máximo resultado com o mínimo de dispêndio [...]" (SAVIANI, 2008, p. 297).

Esses cursos haviam surgido na década anterior, mais especificamente a partir de 1964, quando o conselheiro Newton Sucupira, por meio de uma indicação no CFE, propôs a implantação de licenciaturas em caráter especial, visando formar professores nas áreas de Letras, Estudos Sociais e Ciências para o ginásio. Foi fundamentado nesse modelo de formação que surgiu a ideia do professor polivalente. Modelo que foi retomado na década de 1970 por outro conselheiro, Valnir Chagas (NASCIMENTO, 2012).

Mostra-se precípuo ressaltar que a formação de professores polivalentes em Ciências foi regulamentada por meio da Resolução $n^{\circ}$ 30/74 - CFE, que fixou o currículo mínimo de 1.800 horas para formar profissionais dessa disciplina ministrada no Primeiro Grau. Nas matrizes curriculares desses cursos estavam inclusas as disciplinas de Física, Química, Biologia, Matemática e Geologia, de modo que, para atuar no Segundo Grau, o professor deveria continuar os estudos por mais dois anos, habilitando-se em uma disciplina específica, conforme sua opção (SILVA, 2004).

Krasilchik (2000), ao analisar as influências da Lei n 5.692/71 no Ensino de Ciências, destaca que, no contexto do projeto nacional do governo militar, esse ensino era considerado um importante componente na preparação de trabalhadores qualificados. Todavia, enquanto a legislação valorizava essas disciplinas, na prática elas foram bastante prejudicadas pela criação de disciplinas que pretendiam possibilitar aos estudantes 0 ingresso no mundo do trabalho, de modo que a formação básica ficou comprometida sem que houvesse benefício para a profissionalização.

Outra constatação evidenciada foi o fato do sistema educacional brasileiro ter convivido, durante as décadas de 1960 e 1970, com um vasto leque de possibilidades formativas para os docentes. Esses modelos, por sua vez, continuaram a coexistir em grande parte até a década de 1980, retratando, segundo Saviani (2009), a precariedade em que se encontrava o sistema de formação de professores no país, caracterizado por 
formações aligeiradas e com a ausência de diretrizes que norteassem a implantação de uma política nacional de formação docente em nível superior.

O final dos anos de 1970 foi marcado por uma severa crise econômica e por manifestações de diversos movimentos populares que passaram a exigir a redemocratização do país. Nesse período houve grande preocupação em relação ao ensino e à aprendizagem dos conteúdos científicos, bem como ao desenvolvimento de habilidades científicas pelos estudantes, visto que o país necessitava estar preparado científica e tecnologicamente para competir com as grandes potências econômicas. Nesse sentido, preconizava-se uma urgente reformulação do sistema educacional brasileiro, de modo a garantir que as escolas oferecessem conhecimentos básicos aos cidadãos e colaborassem com a formação de uma elite intelectual que pudesse enfrentar - com maior possibilidade de êxito - os desafios impostos pelo desenvolvimento (KRASILCHIK, 2004).

\section{A efervescência de discussões a partir da década de 1980}

De acordo com Frigotto (2003), na década de 1980 a situação se apresentava insustentável, havendo a necessidade de redimensionar o setor educacional mediante novas propostas formativas que superassem o modelo tecnicista proposto até então. Esse autor destaca que conferências, debates e publicações desenvolvidas nesta época sinalizavam o surgimento de novas perspectivas sobre o fenômeno educacional. Todavia, somente com o fim do regime militar, novas propostas para mudar os rumos das políticas educacionais iriam aparecer.

Essa década foi marcada por profundas transformações políticas, econômicas e sociais no país, dentre as quais se destacam o retorno da democracia (1985), a severa crise econômica (resultante do pagamento das dívidas externas contraídas em nome do desenvolvimento), a massificação da escola e a promulgação da Constituição de 1988. Nesse contexto, Nascimento, Fernandes e Mendonça (2010) ressaltam que a educação passa a ser compreendida como uma prática social em íntima ligação com o contexto político-econômico, de modo que o Ensino de Ciências, a partir de uma perspectiva crítica, é percebido como peça contribuinte para a manutenção da situação vigente no país ou para a sua transformação, dependendo do modo como fosse abordado.

Nas discussões que se avolumaram nesse período, a universidade passa a assumir papel de destaque, sendo criticada não apenas pela formação que oferecia, mas principalmente por sua falta de compromisso com a reconstrução da escola pública. Nesse período, devido à pluralidade de concepções inerentes às relações entre ensino, aprendizagem e desenvolvimento do país, passou-se a considerar como essencial a oferta de programas de educação continuada aos professores, para que se mantivessem atualizados e pudessem acompanhar os avanços das ciências, das tecnologias e as complexas mudanças que caracterizavam a sociedade (VIANNA, 2004).

Nesse âmbito de crescentes discussões, foi aprovada a Indicação $n^{\circ}$ 8/86 MEC/CFE, que propunha a extinção dos cursos de licenciatura de curta duração nas grandes capitais do país (GATTI; BARRETO, 2009). A partir disso, mudar a formação oferecida aos professores se tornou uma prioridade para a melhoria do Ensino de Ciências e das demais disciplinas como um todo, o que favoreceu o surgimento de diversas 
propostas elaboradas por especialistas ligados às universidades públicas do país, tais como cursos de aperfeiçoamento didático, programas de formação continuada, projetos de educação científica, entre outros (NASCIMENTO, 2009).

Também nessa década houve um abandono dos grandes projetos (kits de Ciências, laboratórios, etc.), desenvolvidos em sala de aula, e surgiu um movimento de pequenos projetos, centrados na escola e no professor. Esse processo de ressignificação, por sua vez, não conseguiu atingir os cursos de licenciatura, que continuaram privilegiando em sua estrutura curricular, sobretudo, a formação na área específica, com uma complementação pedagógica ao final do curso, de modo que o licenciado ficava entre duas formações estanques, "[...] com identidade problemática: especialista em área específica ou professor? Matemático ou professor de Matemática? Geógrafo ou professor de geografia? Físico ou professor de física?" (GATTI, 1992, p. 71).

No intuito de solucionar esta problemática, e tendo em vista uma reestruturação curricular das Licenciaturas, foram importantes, para os cursos que formavam os professores de Ciências, os debates promovidos "[...] sobre as mudanças no contexto da disciplina de didática para futuros licenciados [...]" e a proposta de "[...] inserção de outras disciplinas, as quais pudessem dar suporte à construção de um novo currículo que contemplasse uma formação calcada em uma prática pedagógica inserida no contexto social da escola" (MESQUITA; SOARES, 2011, p. 172). Essas mudanças, no entanto, não atingiram o plano prático, permanecendo no âmbito das discussões.

Diante desses acontecimentos, pode-se destacar que a década de 1980, pelo menos no âmbito legal e das discussões acadêmicas, representou uma ruptura com o pensamento tecnicista que predominava na área até então, de modo que os educadores começaram a produzir e evidenciar perspectivas avançadas sobre formação docente, aderindo a uma concepção emancipadora de educação (FREITAS, 2002).

Na efervescência dessas ideias, adentraram-se os anos de 1990 com a incumbência de regulamentar a educação brasileira mediante a construção de uma nova LDB (Lei $n^{\circ}$ 9.394/96) que coadunasse com as perspectivas do século XXI. Chamada de 'Década da Educação', os anos de 1990 assumiram a qualidade e a eficiência como principal bandeira. Nesse período foi implantada uma série de reformas de cunho neoliberal que buscavam atender as exigências de órgãos financiadores internacionais, como o Banco Mundial (MESQUITA; CARDOSO; SOARES, 2013).

Com a LDB n 9.394/96, os sistemas escolares assumiram uma nova organização, em níveis e modalidades: Educação Básica - educação infantil, ensino fundamental (de oito anos ${ }^{1}$ ) e ensino médio (de três anos) - e Educação Superior. Posteriormente, foram lançados diversos pareceres - n० 04/98, n 15/98, n²2/98 - que instituíram as Diretrizes Curriculares Nacionais para o Ensino Fundamental, Ensino Médio e Educação Infantil, respectivamente. Essas diretrizes fixaram normas para elaboração da base curricular nacional da Educação Básica, com as disciplinas assumindo a organização por área do conhecimento (Linguagens, Códigos e suas tecnologias; Ciências Humanas e suas tecnologias; e Ciências da Natureza, Matemática e suas tecnologias). Nesse mesmo período foram promulgados também os Parâmetros Curriculares Nacionais (para o Ensino

\footnotetext{
${ }^{1}$ Pela Lei $n^{\circ} 11.274$, de 06 de fevereiro de 2006, foi ampliado para nove anos.
} 
Fundamental, em 1998, e para o Ensino Médio, no ano 2000), contemplando as orientações para estruturação curricular das disciplinas escolares em cada nível de ensino, ressaltando as competências e habilidades a serem atingidas pelos educandos a cada etapa escolar.

No tocante à formação de professores, a LDB no 9.394/96 regulamentou como "[...] requisito mínimo para a docência na Educação Básica a formação em curso de licenciatura, de graduação plena, em Universidades e Institutos Superiores de Educação" (BRASIL, 1996), o que contribuiu para o aumento da demanda por cursos de Licenciatura em Química (MESQUITA; CARDOSO; SOARES, 2013), visto que, segundo dados do INEP (Tabela 1), durante toda a década de 1990, o número de graduados aptos a exercer a docência nessa disciplina mostrou-se bastante inferior às demais, excluindo-se a Física (RUIZ; RAMOS; HINGEL, 2007). Essas informações evidenciaram um déficit de quase 10 mil professores para lecionar Química no Ensino Médio, e mais de 40 mil quando se adiciona a esta demanda o número da exiguidade de professores para atuar no $2^{\circ}$ ciclo do Ensino Fundamental.

Tabela 1: Demanda de professores e número de licenciados entre 1990 e 2001, por disciplina

\begin{tabular}{lccc}
\hline & \multicolumn{2}{c}{ DEMANDA DE PROFESSORES PARA O } & NÚMERO DE \\
\cline { 2 - 3 } \multicolumn{1}{c}{ DISCIPLINA } & ENSINO MÉDIO & $\begin{array}{c}\text { ENSINO MÉDIO + } \\
\text { 20 CICLO DO ENSINO } \\
\text { FUNDAMENTAL }\end{array}$ & $\begin{array}{c}\text { LICENCIADOS } \\
\text { ENTRE 1990-2001 }\end{array}$ \\
\cline { 2 - 3 } Língua Portuguesa & 47.027 & 142.179 & 52.829 \\
Matemática & 35.270 & 106.634 & 55.334 \\
Biologia & 23.514 & 55.231 & 53.294 \\
Física & 23.514 & 55.231 & 7.216 \\
Química & 23.514 & 55.231 & 13.559 \\
Língua Estrangeira & 11.757 & 59.333 & 38.410 \\
Educação Física & 11.757 & 59.333 & 76.666 \\
Educação Artística & 11.757 & 35.545 & 31.464 \\
História & 23.514 & 71.089 & 74.666 \\
Geografia & 23.514 & 71.089 & 53.509 \\
\hline \multicolumn{1}{c}{ TOTAL } & 235.135 & 710.893 & 456.947 \\
\hline
\end{tabular}

Fonte: RUIZ; RAMOS; HINGEL (2007, p. 11).

Uma das novidades dessa regulamentação diz respeito à criação dos Institutos Superiores de Educação, como uma nova opção de formar professores para atuar na Educação Básica, ficando estabelecido que essas instituições poderiam também manter o Curso Normal Superior, o qual era destinado à formação dos profissionais que iriam lecionar na educação infantil e nas quatro primeiras séries do nível fundamental (BRASIL, 1996).

Com essa regulamentação, passou-se a distinguir as universidades de ensino e as universidades de pesquisa, de modo que os Institutos Superiores de Educação (caracterizados como instituições de caráter técnico-profissionalizante que tinham por objetivo principal a formação de professores com ênfase no caráter técnico instrumental, com competências determinadas para solucionar problemas da prática cotidiana) ficaram 
responsáveis pela formação dos profissionais do magistério, caracterizando-se como uma via de formação aligeirada e mais barata que os cursos de licenciatura e pedagogia (FREITAS, 1999). Essas instituições passaram a sofrer uma maior expansão a partir de 1998, após o Decreto n².306/97 que organizou academicamente todas as Instituições de Ensino Superior (IES) (BRASIL, 1997).

Sobre esse aumento substancial do número de IES a ofertar cursos de formação de professores, principalmente aqueles cujo mercado apresentava uma maior demanda, Freitas (2002) salienta que o processo de implantação dessas instituições foi efetivado de uma forma desordenada e, portanto, sua qualidade ficou comprometida. Um agravante foi o fato dessa situação estar condicionada à crescente expansão do setor privado que, segundo Oliveira et al. (2008), cresceu 59 vezes no período de 1994 a 2002, em contraposição a um aumento de 20 vezes do setor público. Um adendo, entretanto, deve ser inserido em relação às instituições privadas, haja vista que, nesse período, os cursos de formação de professores de Química foram assumidos quase que exclusivamente pelas IES públicas.

Vale salientar que a predominância do setor público na oferta de cursos de Licenciatura em Química tem se perpetuado, muito embora se observe que as instituições privadas também vêm desempenhando seu papel nesse campo de ação. Essa constatação pôde ser comprovada por meio de dados obtidos em uma pesquisa que analisou estatisticamente os cursos de Licenciatura em Química entre os anos 2000 e 2012 no Brasil. Os resultados revelaram que o setor público formou 14,3 mil licenciados em Química nos cursos presenciais, enquanto o setor privado diplomou 9,7 mil egressos no mesmo período (JESUS; ARAÚJO; VIANNA, 2014).

Essa profusão de cursos de licenciatura pode estar relacionada à aprovação, em 2001, das Diretrizes Curriculares Nacionais para a Formação de Professores da Educação Básica em nível superior (graduação plena) de licenciatura (BRASIL, 2002b). Neste mesmo ano, foram também estabelecidas as Diretrizes Curriculares para quase todos os cursos de Graduação, passando a serem aprovadas nos anos subsequentes. As Diretrizes Curriculares Nacionais para os Cursos de Química (DCNCQ), integrantes do Parecer $\mathrm{n}^{\circ}$ 1.303/2001 (BRASIL, 2001), estabeleceram o perfil dos bacharéis e licenciados em Química, tratando-se, portanto, da primeira tentativa de desvincular os cursos de Licenciatura em Química do respectivo bacharelado, visto que determinava as competências e as habilidades dos formandos em cada modalidade.

De acordo com Gatti (2010), poucas mudanças puderam ser observadas nos cursos de licenciatura a partir da implementação dessas diretrizes, de modo que algumas nuances no referido período podem ser destacadas:

[...] Mesmo com ajustes parciais em razão das novas diretrizes, verifica-se nas licenciaturas dos professores especialistas a prevalência da histórica ideia de oferecimento de formação com foco na área disciplinar específica, com pequeno espaço para a formação pedagógica. Adentramos o século XXI em uma condição de formação de professores nas áreas disciplinares em que, mesmo com as orientações mais integradoras quanto à relação "formação disciplinar/formação para a docência", na prática ainda se verifica a prevalência do modelo consagrado no início do século XX para essas licenciaturas [...] (GATTI, 2010, p. 1357). 
É neste contexto ambivalente que o século XXI advém com a implementação de inúmeras reformas, medidas e/ou regulamentações, dentre as quais se destacam, ainda, os Parâmetros Curriculares Nacionais e as Diretrizes Curriculares Nacionais para a Educação Superior, para a Educação de Jovens e Adultos, para a Educação Profissional e Tecnológica, dentre outros. Além de inúmeras alterações na LDB n 9.394/96, em um processo contínuo de harmonias e contradições (FREITAS, 2002).

Todavia, em meio a este constante processo de reformulação, mais de 20 anos após a promulgação da última LDB, ainda não se alcançou o feito de formar os docentes para atuar na Educação Básica exclusivamente em curso de licenciatura, visto que, segundo dados do INEP, no ano de 2016, apenas $77,5 \%$ dos docentes brasileiros possuíam curso superior, sendo que destes, somente $54,9 \%$ possuíam licenciatura na área em que atuavam. No tocante ao Ensino de Química, a situação é ainda mais crítica, visto que apenas 44,0\% dos docentes atuantes são licenciados na disciplina (OBSERVATÓRIO DO PNE, 2017).

Essa característica é ressaltada em um cenário de aumento gradativo da oferta de cursos de Licenciatura em Química por todo o país, uma vez que dados do último censo da Educação Superior, relativos ao ano de 2016, revelaram que existem atualmente 194 instituições brasileiras oferecendo cerca de 355 cursos de Licenciatura em Química (INEP, 2017). Todavia, em meio a esse contexto de ampliação, contraditoriamente esses cursos apresentam um dos maiores índices de evasão e de vagas ociosas. Em contrapartida, esse mesmo censo revela que os cursos de bacharelado mantêm sua predominância na Educação Superior do país, com uma participação de 69,0\% das matrículas.

\section{Considerações finais}

De acordo com o breve percurso histórico apresentado neste escrito, observa-se que os cursos de formação de professores no Brasil (Licenciaturas), ainda convivem com os vestígios históricos e a herança disciplinar dos cursos de bacharelado que estão na origem de sua constituição, embora o artigo $7^{\circ}$ da Resolução $n^{\circ}$ 001/2002-CNE/CP/MEC determine que os Cursos de Licenciatura devam construir sua identidade própria, ou seja, desvincularse de seus respectivos cursos de bacharelado. Deste modo, apesar da maioria das instituições de ensino superior, que oferecem cursos de formação de professores, já terem se adequado a essa exigência, na prática, as mudanças ainda se mostram bastante sutis, sobretudo nos cursos que compõem a área das Ciências da Natureza, como o de Química.

Compreende-se, portanto, que a identidade bacharelesca dos cursos de Educação Superior ainda ocupa grande espaço no seio dos cursos de licenciatura e, no tocante aos cursos de Licenciatura em Química, observa-se que o aumento da oferta do número de vagas não veio acompanhado de uma reestruturação curricular efetiva, de modo que os problemas continuam se avolumando. Nesse sentido, os índices que avaliam a educação brasileira demonstram que a precariedade das políticas formativas, implantadas no decorrer da história educacional, revelam-se permanentes, de modo que as sucessivas mudanças estabelecidas não conseguiram assegurar um padrão mínimo de preparo docente para fazer face aos problemas enfrentados pela educação escolar do país.

Pode-se identificar, portanto, que o cenário geral da formação de professores no Brasil não é animador. Diversas pesquisas realizadas a nível nacional confirmam esta 
conclusão, além de reiterarem que os impasses e problemas construídos e acumulados historicamente na formação de professores em nível superior no Brasil precisam ser enfrentados (GATTI; BARRETTO; ANDRÉ, 2011; DINIZ-PEREIRA, 2011; LIBÂNEO, 2010; GATTI; BARRETTO, 2009; FREITAS, 2007; GATTI, 2014).

Por fim, concorda-se com a perspectiva de Freitas (2007) acerca da necessidade de implantação de uma política global de formação e valorização dos profissionais da educação. Uma política que contemple de forma articulada e prioritária a formação inicial, formação continuada e condições de trabalho, salários e carreira, com a concepção sóciohistórica do educador. Um movimento que continua a fazer parte das utopias e do ideário dos educadores e das lutas pela educação pública dos últimos 30 anos.

\section{Referências}

ARANHA, M. L. de. História da educação e da pedagogia: Geral e Brasil. 3. ed. São Paulo: Moderna, 2006.

BARRA, V. M.; LORENZ, K. M. Produção de materiais didáticos de ciências no Brasil, período: 1950 a 1980. Ciência e Cultura, São Paulo, Brasil: Sociedade Brasileira para o Progresso da Ciência, v. 38, n. 12, p. 1970-1983, dez. 1986. Disponível em: $<$ http://digitalcommons.sacredheart.edu/cgi/viewcontent.cgi?article=1045\&context=cedfa> Acesso em: 05 set. 2017.

BARROSO, H. M.; FERNANDES, I. R. Observatório universitário: uma nota técnica sobre a criação de universidades, por categoria administrativa e gestão política. Dezembro 2006. Disponível em: <http://www.observatoriouniversitario.org.br/documentos_de_trabalho/ documentos_de_trabalho_62.pdf>. Acesso em: 25 out. 2017.

BRASIL. Criação de universidades. 2017. Disponível em: <http://portal.mec.gov.br/sesu/arquivos/pdf/linhatempo-ifes.pdf>. Acesso em: 25 out. 2017.

. Ministério da Educação. Lei no 11.274 de 06 de fevereiro de 2006. Altera a redação dos arts. 29, 30, 32 e 87 da Lei no 9.394, de 20 de dezembro de 1996, que estabelece as diretrizes e bases da educação nacional, dispondo sobre a duração de 9 (nove) anos para o ensino fundamental, com matrícula obrigatória a partir dos 6 (seis) anos de idade. Diário Oficial [da] República Federativa do Brasil, Brasília, DF, 07 fev. 2006, Seção 1, p. 3. Disponível em: http://www2.camara.leg.br/legin/fed/lei/2006/lei-11274-6-fevereiro-2006540875-publicacaooriginal-42348-pl.html. Acesso em: 05 dez. 2017.

Conselho Nacional de Educação. Resolução CNE/CP n 1, de 18 de fevereiro de 2002. Institui as Diretrizes Curriculares Nacionais para a Formação de Professores da Educação Básica, em nível superior, curso de licenciatura, de graduação plena. Diário Oficial [da] República Federativa do Brasil, Brasília, DF, 09 abr. 2002a, Seção 1, p. 31. Disponível em: http://portal.mec.gov.br/cne/arquivos/pdf/rcp01_02.pdf. Acesso em: 05 jun. 2017.

Conselho Nacional de Educação. Resolução CES/CNE nº 08, de 11 de março de 2002. Estabelece as Diretrizes Curriculares para os cursos de Bacharelado e Licenciatura em Química. Diário Oficial [da] República Federativa do Brasil, Brasília, DF, 26 mar. 
2002b, Seção 1, p. 13. Disponível em: http://portal.mec.gov.br/cne/arquivos/pdf/CES082002.pdf. Acesso em: 24 out. 2017.

Conselho Nacional de Educação. Parecer CNE/CES n 1.303, de 04 de dezembro de 2001. Estabelece as Diretrizes Curriculares Nacionais para os cursos de Química. Diário Oficial [da] República Federativa do Brasil, Brasília, DF, 07 dez. 2001, Seção 1, p. 25. Disponível em: http://portal.mec.gov.br/cne/arquivos/pdf/CES1303.pdf. Acesso em: 24 out. 2017.

Conselho Nacional de Educação. Parecer CNE/CEB n 04 de 29 de janeiro de 1998. Estabelece as Diretrizes Curriculares Nacionais para o Ensino Fundamental. Diário Oficial [da] República Federativa do Brasil, Brasília, DF, 30 mar. 1998, Seção 1, p. 25. Disponível em: http://portal.mec.gov.br/cne/arquivos/pdf/1998/pceb004_98.pdf. Acesso em: 05 dez. 2017.

Conselho Nacional de Educação. Parecer CNE/CEB no 15 de 01 de junho de 1998. Estabelece as Diretrizes Curriculares Nacionais para o Ensino Médio. Diário Oficial [da] República Federativa do Brasil, Brasília, DF, 26 jun. 1998, Seção 1, p. 8. Disponível em: http://portal.mec.gov.br/cne/arquivos/pdf/1998/pceb015_98.pdf. Acesso em: 05 dez. 2017.

Conselho Nacional de Educação. Parecer CNE/CEB n 22 de 17 de dezembro de 1998. Estabelece as Diretrizes Curriculares Nacionais para a Educação Infantil. Diário Oficial [da] República Federativa do Brasil, Brasília, DF, 23 mar. 1999, Seção 1, p. 8. Disponível em: http://portal.mec.gov.br/dmdocuments/parecer_ceb_22.98.pdf. Acesso em: 05 dez. 2017.

Ministério da Educação. Decreto $\mathrm{n}^{\circ}$ 2.306, de 19 de agosto de 1997. Regulamentação das instituições de ensino superior. Diário Oficial [da] República Federativa do Brasil, Brasília, DF, 20 ago. 1997. Seção1, p. 17991. Disponível em: http://www.planalto.gov.br/ccivil_03/decreto/d2306.htm. Acesso em: 20 jul. 2017.

. Ministério da Educação. Lei no 9.394 de 20 de dezembro de 1996. Estabelece as diretrizes e bases da Educação nacional. Diário Oficial [da] República Federativa do Brasil, Poder Executivo, Brasília, DF, 23 dez. 1996. Seção 1, p. 27833. Disponível em: http://www.planalto.gov.br/ccivil_03/leis/L9394.htm. Acesso em: 22 jul. 2017.

. Ministério da Educação. Lei n 5.692, de 11 de agosto de 1971. Fixa Diretrizes e Bases para o ensino de $1^{\circ}$ e $2^{\circ}$ graus, e dá outras providências. Diário Oficial [da] República Federativa do Brasil, Poder Executivo, Brasília, DF, 12 ago. 1971. Seção 1, p. 6592. Disponível em: http://www.planalto.gov.br/ccivil_03/leis/L5692.htm. Acesso em: 24 out. 2017.

Ministério da Educação. Lei no 5.540, de 28 de novembro de 1968. Fixa normas de organização e funcionamento do ensino superior e sua articulação com a escola média, e dá outras providências. Diário Oficial [da] República Federativa do Brasil, Poder Executivo, Brasília, DF, 29 nov. 1968. Seção 1, p. 10369. Disponível em: http://www.planalto.gov.br/ccivil_03/leis/L5540.htm. Acesso em: 24 out. 2017.

Ministério da Educação. Lei o 4.024, de 20 de dezembro de 1961. Fixa as Diretrizes e Bases da Educação Nacional. Diário Oficial [da] República Federativa do 
Brasil, Poder Executivo, Brasília, DF, 27 dez. 1961. Seção 1, p. 11429. Disponível em: http://www.planalto.gov.br/ccivil_03/leis/L4024.htm. Acesso em: 24 out. 2017.

- Ministério da Educação. Decreto-Lei n 9.355, de 13 de junho de 1946. Funda o Instituto Brasileiro de Educação, Ciência e Cultura. Diário Oficial [da] República Federativa do Brasil, Poder Executivo, Brasília, DF, 15 jun. 1946. Seção 1, p. 8991. Disponível em: http://www2.camara.leg.br/legin/fed/declei/1940-1949/decreto-lei-9355-13junho-1946-417468-publicacaooriginal-1-pe.html. Acesso em: 24 out. 2017.

. Ministério da Educação. Decreto-Lei n 4.244, de 09 de abril de 1942. Lei Orgânica do Ensino Secundário. Diário Oficial [da] República Federativa do Brasil, Poder Executivo, Brasília, DF, 10 abr. 1942. Seção 1, p. 5798. Disponível em: http://www2.camara.leg.br/legin/fed/declei/1940-1949/decreto-lei-4244-9-abril-1942 4141 55 -publicacaooriginal-1-pe.html. Acesso em: 24 out. 2017.

Ministério da Educação. Decreto-Lei n 1.190, de 04 de abril de 1939. Dá organização à Faculdade Nacional de Filosofia. Diário Oficial [da] República Federativa do Brasil, Poder Executivo, Brasília, DF, 06 abr. 1939. Seção 1, p. 7929. Disponível em: http://www2.camara.leg.br/legin/fed/declei/1930-1939/decreto-lei-1190-4-abril-19393492 41-publicacaooriginal-1-pe.html. Acesso em: 24 out. 2017.

Ministério da Educação. Decreto-Lei n 19.851, de 11 de abril de 1931. Dispõe sobre a organização do Ensino Superior. Diário Oficial [da] República Federativa do Brasil, Poder Executivo, Brasília, DF, 15 abr. 1931a. Seção 1, p. 5800. Disponível em: http://www2.camara.leg.br/legin/fed/decret/1930-1939/decreto-19851-11-abril-1931-5058 37-norma-pe.html. Acesso em: 24 out. 2017.

Ministério da Educação. Decreto-Lei n 19.890, de 18 de abril de 1931. Dispõe sobre a organização do ensino secundário. Diário Oficial [da] República Federativa do Brasil, Poder Executivo, Brasília, DF, 01 mai. 1931b. Seção 1, p. 6945. Disponível em: http://www.planalto.gov.br/ccivil_03/decreto/1930-1949/D19890.htm. Acesso em: 23 out. 2017.

CANDAU, V. M. (Coord.). Novos rumos da licenciatura: relatório de pesquisa. Rio de Janeiro: PUCRJ, 1988.

CHARLOT, B. Educação e Globalização: uma tentativa de colocar ordem no debate. Sísifo: Revista de Ciências da Educação, São Paulo, n. 4, p. 129-136, out./dez. 2007. Disponível em: https://moodle.fct.unl.pt/pluginfile.php/32501/mod_glossary/attachment/10671/ Bernadr_charlot.pdf. Acesso em: 14 out. 2017.

CHASSOT, Á. Para que(m) é útil o ensino? Alternativas para um (ensino de Química) mais crítico. 2. ed. Canoas - RS: ULBRA, 2004.

DIAS-DA-SILVA, M. H. G. F. Política de formação de professores no Brasil: as ciladas da reestruturação das licenciaturas. Perspectiva, Florianópolis, v. 23, n. 02, p. 381-406, jul./dez. 2005. Disponível em: https://periodicos.ufsc.br/index.php/perspectiva/article /view/9763/8995. Acesso em: 10 jun. 2017.

DINIZ-PEREIRA, J. E. O ovo ou a galinha: a crise da profissão docente e a aparente falta de perspectiva para a educação brasileira. Revista Brasileira de Estudos Pedagógicos, Brasília, v. 92, n. 230, p. 34-51, jan./abr. 2011. Disponível em: 
http://rbep.inep.gov.br/index.php/rbep/article/view/541/524. Acesso em: 10 jun. 2017.

FREITAS, H. C. L. de. A (nova) política de formação de professores: a prioridade postergada. Educação \& Sociedade, Campinas, v. 28, n. 100 - Especial, p. 1203-1230, out. 2007. Disponível em: http://www.scielo.br/pdf/es/v28n100/a2628100.pdf. Acesso em: 10 jun. 2017.

Formação de professores no Brasil: 10 anos de embate entre projetos de formação. Educação \& Sociedade, Campinas, v. 23, n. 80, p. 136-167, set. 2002. Disponível em: http://www.scielo.br/pdf/es/v23n80/12928.pdf. Acesso em: 14 ago. 2017.

A reforma do Ensino Superior no campo da formação dos profissionais da educação básica: as políticas educacionais e os movimentos dos educadores. Educação e Sociedade, Campinas, ano XX, n. 68, p. 17-44, dez. 1999. Disponível em: http://www. scielo.br/pdf/es/v20n68/a02v2068.pdf. Acesso em: 10 jun. 2017.

FRIGOTTO, G. Educação e a crise do Capitalismo Real. 5. ed, São Paulo: Cortez, 2003.

GATTI, B. A formação inicial de professores para a educação básica: as licenciaturas. Revista USP, São Paulo, n. 100, p. 33-46, dez./jan./fev. 2013-2014. Disponível em: https://www.revistas.usp.br/revusp/article/viewFile/76164/79909. Acesso em: 21 out. 2017.

Formação de professores no Brasil: características e problemas. Educação \& Sociedade, Campinas, v. 31, n. 113, p. 1355-1379, out./dez. 2010. Disponível em: http://www.scielo.br/pdf/es/v31n113/16.pdf. Acesso em: 20 out. 2017.

. A formação dos docentes: 0 confronto necessário professor $x$ academia. Cadernos de Pesquisa, São Paulo, n. 81, p. 70-74, mai. 1992. Disponível em: http://publicacoes.fcc.org.br/ojs/index.php/cp/article/view/993. Acesso em: 20 ago. 2017.

GATTI, B. A.; BARRETTO, E. S. de S.; ANDRÉ, M. E. D. de A. Políticas Docentes no Brasil: um Estado da Arte. Brasília: UNESCO, 2011.

GATTI, B. A.; BARRETTO, E. S. de S. Professores do Brasil: impasses e desafios. Brasília: UNESCO, 2009.

IMBERNÓN, F. Formação docente e profissional: formar-se para a mudança e a incerteza. 9. ed. São Paulo: Cortez, 2011.

INEP. Sinopse Estatística da Educação Superior 2016. [online]. Brasília: Inep, 2017. Disponível em: http://portal.inep.gov.br/web/guest/sinopses-estatisticas-da-educacaosuperior. Acesso em: 10 out. 2017.

JESUS, W. S.; ARAUJO, R. S.; VIANNA D. M. Formação de Professores de Química: a Realidade dos Cursos de Licenciatura Segundo os Dados Estatísticos. Scientia Plena. Aracaju, v. 10, n. 08, 2014. Disponível em: https://www.scientiaplena.org.br/ sp/article/view/2015. Acesso em: 20 out. 2017.

KRASILCHIK, M. Prática de Ensino de Biologia. 4. ed. São Paulo: EdUSP, 2004.

Reformas e realidade: o caso do ensino das ciências. São Paulo em Perspectiva, São Paulo, v. 14, n. 1, p. 85-93, jan./mar. 2000. Disponível em: http://www.scielo.br/pdf/spp/ v14n1/9805.pdf. Acesso em: 21 jun. 2017.

LIBÂNEO, J. C. Formação de Professores e Didática para Desenvolvimento Humano. 
Educação \& Realidade, Porto Alegre, v. 40, n. 2, p. 629-650, jun. 2015. Disponível em: http://www.scielo.br/pdf/edreal/2015nahead/2175-6236-edreal-46132.pdf. Acesso em: 07 set. 2017.

. O Ensino da Didática, das Metodologias Específicas e dos Conteúdos Específicos do Ensino Fundamental nos Currículos dos Cursos de Pedagogia. Revista Brasileira de Estudos Pedagógicos, Brasília, v. 91, n. 229, p. 562-83, set./dez. 2010. Disponível em: http://rbep.inep.gov.br/index.php/rbep/article/view/630/610. Acesso em: 10 jun. 2017.

LORENZ, K. M. Ação de instituições estrangeiras e nacionais no desenvolvimento de materiais didáticos de ciências no Brasil: 1960-1980. Revista Educação em Questão, Natal, v. 31, n. 17, p. 7-23, jan./abr. 2008. Disponível em: https://periodicos.ufrn.br/ educacaoemquestao/article/view/3903. Acesso em: 05 ago. 2017.

MENDONÇA, A. W. P. C. A universidade no Brasil. Revista Brasileira de Educação, Rio de Janeiro, n. 14, p. 131-194, mai./ago. 2000. Disponível em: http://www.scielo.br/ pdf/rbedu/n14/n14a08. Acesso em: 25 out. 2017.

MESQUITA, N. A. da S.; CARDOSO, T. M. G.; SOARES, M. H. F. B. O projeto de educação instituído a partir de 1990: caminhos percorridos na formação de professores de química no Brasil. Química Nova, São Paulo, v. 36, n. 1, p. 195-200, fev. 2013. Disponível em: http://www.scielo.br/pdf/qn/v36n1/v36n1a33.pdf. Acesso em: 22 jun. 2017.

MESQUITA, N. A. da S.; SOARES, M. H. F. B. Aspectos históricos dos cursos de licenciatura em química no Brasil nas décadas de 1930 a 1980. Química Nova, São Paulo, v. 34, n. 1, p. 165-174, fev. 2011. Disponível em: http://www.scielo.br/scielo.php? script=sciarttext\&pid=S0100-40422011000100031. Acesso em: 15 set. 2017.

NARDI, R. Memórias da educação em ciências no Brasil a pesquisa em ensino de física. Investigações em Ensino de Ciências, Porto Alegre, v. 10, n. 1, p. 63-101, mar. 2005. Disponível em: https://www.if.ufrgs.br/cref/ojs/index.php/ienci/article/download/523/319. Acesso em: 26 out. 2017.

NASCIMENTO, F. do. Pressuposto para a formação crítico-reflexiva de professores de ciências na sociedade do conhecimento. In: MIZUKAMI, M. da G. N.; REALI, A. M. de M. R. (Orgs.). Teorização de práticas pedagógicas: escola, universidade, pesquisa. São Carlos: UdUFSC, 2009, p. 35-72.

NASCIMENTO, F. do; FERNANDES, H. L.; MENDONÇA, V. M. de. O ensino de ciências no Brasil: história, formação de professores e desafios atuais. HISTEDBR On-line, Campinas, n. 39, p. 225-249, set. 2010. Disponível em: https://periodicos.sbu. unicamp.br/ojs/index.php/histedbr/article/view/8639728/7295. Acesso em: 21 ago. 2017.

NASCIMENTO, T. R. A criação das licenciaturas curtas no Brasil. Revista HISTEDBR Online, Campinas, n. 45, p. 340-346, mar. 2012. Disponível em: http://www.histedbr.fe. unicamp.br/revista/edicoes/45/doc01_45.pdf. Acesso em: 10 jun. 2017.

OBSERVATÓRIO DO PNE. 15 - Formação de professores. Disponível em: http://www. observatoriodopne.org.br/metas-pne/15-formacao-professores. Acesso em: 02 ago. 2017.

OLIVEIRA, J. F. de.; CATANI, A. M.; HEY, A. P.; AZEVEDO, M. L. N. de. Democratização do acesso e inclusão na educação superior no Brasil. In: BITTAR, M.; OLIVEIRA, J. F. de; 
MOROSINI, M. (Orgs.). Educação Superior no Brasil - 10 anos pós-LDB. Brasília: INEP, 2008. p. 71-88.

OSÓRIO, V. K. L.; Alameda Glette, 463, sede do Curso de Química da Universidade de São Paulo no período 1939-1965. Química Nova, São Paulo, v. 32, n.7, p. 1975-1980, 2009. Disponível em: http://www.scielo.br/pdf/qn/v32n7/49.pdf. Acesso em: 10 jun. 2017.

ROMANELLI, O. de O. História da Educação no Brasil (1930/1973). 32. ed. Petrópolis: Vozes, 2007.

RUIZ, A. I.; RAMOS, M. N.; HINGEL, M. Escassez de professores no ensino médio: propostas estruturais e emergenciais. CNE/CEB, Brasília, DF, 2007.

SAVIANI, D. História das ideias pedagógicas no Brasil. 4. ed. Campinas: Autores Associados, 2013.

Formação de professores: aspectos históricos e teóricos do problema no contexto brasileiro. Revista Brasileira de Educação, Rio de Janeiro, v. 14, n. 40, p. 143-155, jan./abr. 2009. Disponível em: http://www.scielo.br/scielo.php?script=sciarttext\&pid =S1413-24782009000100012. Acesso em: 10 jun. 2017.

. O legado educacional do Regime Militar. Cadernos Cedes, Campinas, v. 28, n. 76, p. 291-312, set./dez. 2008. Disponível em: http://www.scielo.br/pdf/ccedes/v28n76 /a02v2876.pdf. Acesso em: 10 jun. 2017.

SILVA, A. F. da. Formação de professores para a educação básica no Brasil: projetos em disputa (1987-2001). 2004. 392 f. Tese (Doutorado em Educação) - Universidade Federal Fluminense, Niterói, 2004. Disponível em: http://www.bdtd.ndc. uff.br/tdearquivos/2/TDE-2008-01-22T132406Z-1194/Publico/Tese-Andreia\%20Silva.pdf. Acesso em: 16 jun. 2017.

SOUZA, R. F. História da organização do trabalho escolar e do currículo no Século XX: ensino primário e secundário no Brasil. São Paulo: Cortez, 2008.

TERRAZAN, E. A.; DUTRA, E. F.; WINCH, P. G.; SILVA, A. A. Configurações curriculares em cursos de licenciatura e formação identitária de professores. Revista Diálogo Educacional, Curitiba, v. 8, n. 23, p. 71-90, jan./abr. 2008. Disponível em: https://periodicos.pucpr.br/index.php/dialogoeducacional/article/view/3973/3889. Acesso em: 10 jun. 2017.

VIANNA, I. O. de A. A formação de docentes no Brasil: história, desafios atuais e futuros. In: RIVERO, C. M. L.; GALLO, S. (Orgs.). A formação de professores na sociedade do conhecimento, Bauru: EDUSC, 2004, p. 21-54.

VICENTINI, P.; LUGLI, R. S. G.; História da profissão docente no Brasil: representações em disputa. São Paulo: Cortez, 2009.

ZOTTI, S. A. Sociedade, educação e currículo no Brasil: dos jesuítas aos anos de 1980. São Paulo: Autores Associados, 2004.

Submissão: 15/12/2017

Aceite: 02/06/2018 